\title{
Communicating Flood Risk: Looking Back and Forward at Traditional and Social Media Outlets
}

DavidFeldman $^{\text {a*, }}$, Santina Contreras ${ }^{\mathrm{a}}$, Beth Karlin ${ }^{\mathrm{b}}$, Victoria Basolo ${ }^{\mathrm{a}}$, Richard Matthew ${ }^{\mathrm{a}}$, Brett Sanders $^{\mathrm{c}}$, DouglasHouston ${ }^{\mathrm{a}}$, Wing Cheung ${ }^{\mathrm{a}}$, Kristen Goodrich ${ }^{\mathrm{b}}$, Abigail Reyes ${ }^{\mathrm{d}}$, Kimberly Serrano $^{\text {d, }}$, JochenSchubert ${ }^{\mathrm{c}}$, Adam Luke ${ }^{\mathrm{c}}$

${ }^{a}$ Department of Planning, Policy, and Design, University of California, Irvine, CA 92697, USA

${ }^{\mathrm{b}}$ School of Social Ecology, University of California, Irvine, CA 92697, USA

${ }^{\mathrm{c}}$ Department of Civil and Environmental Engineering, University of California, Irvine, CA 92697, USA

${ }^{\mathrm{d}}$ Sustainability Initiative, University of California, Irvine, CA 92697, USA

* Corresponding author: feldmand@uci.edu

\begin{abstract}
The communication of information about natural hazard risks to the public is a difficult task for decision makers. Research suggests that newer forms of technology present useful options for building disaster resilience. However, how effectively these newer forms of media can be used to inform populations of the potential hazard risks in their communityremainsunclear. Thisresearch uses primary data from an in-person surveyof164 residents of Newport Beach, Californiaduring the spring of 2014 to ascertain thecurrent and preferred mechanisms through which individuals receive information on flood risks in their community. Factor analysis of survey data identified two predominant routes of dissemination forrisk information: older traditional media and newer social media sources. A logistic regression model was specified to identify predictors for choosing a particular communication route. This analysis revealed that ageis the central factor in predicting the sources people useto receive risk information. We follow the analysis by discussing this finding and its policy implications.
\end{abstract}

Keywords:Floods, Risk Communication, Risk information, Social Media

\section{Under preparation for the International Journal of Disaster Risk Reduction DRAFT - NOT FOR DISTRIBUTION}




\section{Introduction}

Hazards from coastal flooding are increasing worldwide due to a combination of sealevel rise, more intense tropical storms, and increasedurbanization in coastal zones[1,2]. As a consequence, providing populations living in these vulnerable areas with relevantinformation on the potential hazard risks in their communities is becoming a major policy priority. Moreover, determining how best to deliver this hazard information to increasingly diverse communities presents a serious challenge. Exploring the use of different risk communication channels for addressing this issue is important because individual actions may be motivated by the timing and medium's through which hazard risk and preparedness information is received $[3,4]$. Emergency planners, first responders, residents and public officials in regions subject to flooding need to know: are there specific forms by which risk information can be delivered to communities that might assist in informing residents in flood-prone areas how to avoid, or at least become better prepared to reduce the risks to life and property from flooding?

The current study ${ }^{1}$ aims to expand on past investigations in an effort to further our understanding of the communication of hazard information to flood vulnerable populations. Specifically, we ask (1) what are the current and preferred mechanisms through which individuals in flood vulnerable communities receive information on flood risks in their community, and (2) what individual socioeconomic characteristics predict the selection of particular communication channels. In this study, we focus not on emergency warnings of hazard events, but on the overall communication of flood hazard information to coastal populations, in order to determine what factors predict the selection of a particular communication source.

\footnotetext{
${ }^{1}$ This study analyzes survey data from the larger Flood RISE (Resilient Infrastructure and Sustainable Environments) research project, which aims to promote resilience to coastal flooding in Southern California.
} 


\subsection{Communication of Environmental Hazards}

While significant progress has been made in learning how to partly alleviate and adapt to floods, including limiting development in and around floodplains; relocating at-risk developments; adopting early warning systems to permit those in harm's way to evacuate; and, flood-proofing homes and businesses, understanding how to effectively communicate information to communities on the potential risks of flooding remains a significant challenge. It is important to address this issue, because while abating flood threats through levees and other fortified measures (so-called "structural defense") is a popular response on the part of decisionmakers, these measures are far from entirely effective, making it critical that the public is well aware of the potential risks to their communities.

The communication of information on environmental hazards typicallyinvolvesthe dissemination of different types of hazards information through a variety of sources and channels. Information on environmental hazards can come in the form of descriptions of the relevance of the environmental hazard, explanations of the hazards potential for damage, details on household response options during a hazard event, and recommendations for household preparedness actions[4-7]. Sources and channels through which this information is most often relayed to the public can include government agencies, schools, places of employment, and the mass media [6-10].

In recent decades, experts have offered numerous recommendations on how to most effectively communicate risk fromenvironmental hazards to the general public. These recommendations can be summarized as a series of "dos" and "don'ts" including (1) knowing your audience; (2) not using jargon, acronyms, or euphemisms; (3) keeping the vocabulary as familiar as possible; (4) only using technical terms when absolutely required and defining them 
both at the outset as well as in context, whenever possible (5) developing a simple and easy flow of related ideas; (6) breaking material into logical and understandable parts; (7) adequately developing each concept (i.e., not squeezing too many ideas into a limited space); and (8) summarizing and repeating materials as needed for emphasis or understanding[11-13].

\subsection{Risk Communication: One-way vs. Two-way Processes}

Conceptualizations of the best ways to communicate risk have changed over time, specifically in regards to the incorporation of the public in the risk communication process. In the past, risk communication was seen mostly as a one-way form of communicating, with the public being informed of the most salient risks based on what expertsdeem most critical[14]. This one dimensional model of risk communication has been largely criticized in the literature, and branded as producing an "information deficit" where information is not viewed as trustworthy, credible, or worthy of reposing confidence by the public [15]. For this reason, risk communicators are nowencouragedto regard the communication process as a two way, interactive and long-term process, where the public and experts are engaged in a dialog, rather than acting as, respectively, one dimensional senders and receivers[16,17]. Specifically, risk communication as a two-way process emphasizes: (1) expert focus upon the risks most salient to the average person who is vulnerable to a particular hazard; (2) communicators acknowledging the disparities of power among both information providers and users on one hand (including the distrust with which large-scale organizations may be held), as well as different types of users on the others (e.g. financial backers of a waste incinerator versus home owners); (3) information dissemination in forms that are useful, credible, relevant, and stated in common language for users; (4) the public's concerns with consequence, moral implications of hazards, and that the frequent inequities generated by their burdens be considered as important as their statistical 
probabilities; and, (5) the importance of "delayed" or latent consequences as well as the reversibility or non-reversibility of assessing their impacts [18-22].

In light of these changing views of the objectives and processes of risk communication, risk communication experts now generally agree that it is critical that risk communicators know their audiences, taking time to understand their perspectives[11,13,23] and values [24,25].Krimsky and Plough[26], for instance, emphasize the importance of considering social, cultural, and historical factors in the risk communication process. For example, they suggest that it is important to understand the traditions and even "folk wisdom" of groups in order to know what they can relate to and what is meaningful to them. Other experts[27]warn against the overreliance of usingspecifictypes of information to persuade the public to take a certain view, stressing the need to empower people to make informed decisions about risks that are in their power to control.For this reason risk communication is often viewed as a means to "empower individuals to make informed decisions about the hazards within their control"[27].

Moreover, it is important to understand one's audience in communicating risk due to the fact that the effectiveness of risk communication has been found to be linked to internal factors that affect an individual's capacity to access and use information on risks[28]. There is a wellestablished vulnerability to risk communication due to language barriers, speech or hearing impairment, visual impairment, literacy, and documented citizen status. In order to ensure community resilience to natural disasters, a particular set of risk communication challenges stem from this fact. This set includes: how to address broader issues associated with reducing vulnerability whileenhancing the capacity of the community to manage hazardsby developing flexibility in the community's communication systems to deal with uncertain events; having alternative means of communication/redundancy in the community's systems to provide 
vulnerable populations information; having information translators available who can reach out to people with special communication needs; and, implementing training for organizations and community groups[29]. These issues are becoming increasingly recognized as critical for risk communication of all environmental hazards.

\subsection{Risk Communication Information Channels}

In many affluent coastal communities in developed societies, the potential number of channelsfor receiving risk information is extensive. Traditionally utilized information channels include print sources such as newspapers, magazines, and brochures; electronic sources such as television, radio, telephone, and the Internet; and in person communications [30,31]. In addition to these more establishedcommunication tools, social media sources have been growing as mechanismsfor communicating information on natural hazards. In this context, social media typically refers to Internet-based applications that facilitate the sharing of information from multiple parties on computers and mobile devices, such as social networking sites (e.g. Facebook and Twitter), texting, chatrooms, discussion forums, and blogs[32]. The utilization of these sources has been increasingly utilized by a wide variety of international, national, state, and local organizations. Particularly the use of social media has been growing in its use by government agencies, as it is seen as an effective vehicle for the sharing of formal and informal sources of informationto various audiences, creating a vehicle for effective two-way communication between citizens and governments [33,34].

The increased usage and impact of social media in hazard studies has been discussed in a growing number of studies[32,35]. Much of this work has been particularly focused on the role of social media during disaster events, including during floods[36-42], earthquakes[43-47], hurricanes[48,49], tsunamis[50,51], wildfires[52], and droughts [31].Thus, while social media is 
understood to play a critical role during and immediately following disaster events, there has been less investigation into the use of social media as a pre-event channel for disseminating risk information. Details such as how widespread social media's usage has become amongst different populations remains unclear- as is its desired usability in the future. Researchers note that without evidence-based strategies of how these newer technologies are being used, it remains difficult to know how to best implement social media tools into hazard planning strategies [53].

\subsection{Factors influencing sources utilized for flood risk information}

The sources that residents utilize for flood risk information varyconsiderably according to demographiccharacteristics and local community characteristics that affect flood risk awareness [54]. For example, while the Internet is proving to bean important source of risk information for evacuation in coastal areas - especially among younger cohorts[55], research in Australia has found that the most popular information sourcesin coastal households before and during flood was radio, followed by television [56] - suggesting web-based information sources are not a universal choice for receiving hazard information and the so called "digital divide" remains an issue.

Previous flood experience can play an important role in the communication of flood risk information. Studies have found, for example, that even in communities with well-known flood risks, newer residents may be relatively unaware of hazard potential when buying a home because the information on potential flood risk is simply difficult to comprehend [54]. By contrast, long-time residents may be reluctant to access flood risk information, even when available, because they believe - as a result of experience with low-flood risk experiences - that “it'll never happen to me" [54]. Thus knowing one's audience also means knowing their experience with natural hazards. 
While prior studies provide many insights about risk communication for environmental hazards, important questions concerning flood hazard communication remain unanswered. For example, what types of communication are useful for dissemination of potential vulnerability to flooding? In other words, what kinds of information might help people living in flood-vulnerable regions: 1) know they are vulnerable; 2) understand the extent to which they are subject to serious flooding; and, 3) enable them to better prepare for a flood event? Research has found that public trusttoward different sources of information that might be useful for flood hazard preparation varies considerably. For instance, people generally trust those sources of risk information that are seen as credible, reliable, caring, knowledgeable, expert, and honest[57,58], and information presented must be crafted concisely, via channels felt to be credible by the receiving audience, and must be relevant and able to prescribe some response[59].

\section{Methods}

\subsection{Study Area}

Our study focused on the communities surrounding the Newport Bay Estuary within the city of Newport Beach, California. Thisurbanized, densely developed region is vulnerable to flooding from multiple sources. A large portion of the city is below extreme high tide levels [60]. The community also lies at between an estuary and several small streams - thus, subject to flood hazards from a large rainfall event, streams overflowing their banks, high tides, and sea-level rise. In short, the most severe flooding in the region occurs with coincident streamflow, rainfall, high tides, positive sea level anomalies and waves [61]. Residents living within the study area have a higher median age compared to the county (46.9 years of age versus 36.2 ) and a higher mean annual household income compared to the rest of the county $(\$ 161,766$ versus $\$ 101,134)[62]$. 


\subsection{Survey Procedure}

Surveys were conducted with randomly assigned households in the communitiessurrounding the Newport Bay Estuary. The study area was divided into four subareas (Upper Peninsula, Lower Peninsula, Balboa Island, and Lido Island) based on the distribution of residential parcels and hazard mapping estimates of areas at risk of flooding (Figure 1).

The survey method consisted of an in-person guided survey ${ }^{2}$ administered during the spring of 2014. Outreach was conducted prior to the start of the survey and included the mailing of pre-notice letters describing the study and survey procedures, as well as indicating when the field research team planned to return to conduct the survey. The field research team visited sample households and invited the head of household, 18 years of age or older to participate. Potential respondents were given a choice of completing the survey at that time, scheduling a later time for the research team to return to administer the survey, or refusing to participate. The survey process involved verbally reading a paper survey to participants after which responses were entered into an online survey tool on a tablet device. In cases where there was no access to the Internet, responses were recorded on the paper survey and subsequently transferred to the survey web application. On average surveys lasted approximately 40 to 60 minutes.

The total number of households contacted for participation in the survey was 2448. A total of 217 respondents $(8.9 \%)$ completed the survey. For island sub-areas there was a response rate of 9.2\% (58 respondents) for the Upper Peninsula, 9.7\% (59 respondents) for the Lower Peninsula, 8.8\% (68 respondents) for Balboa Island, and 7.4\% (32 respondents) for Lido Island

\footnotetext{
${ }^{2}$ Surveys were administered by the Newport Beach Field Research Team, which consisted of extensively trained University of California undergraduate students.
} 
(Figure 1$)^{3}$.Analyses were performed on a final sample of 164 , who provided complete responses for relevant socioeconomic characteristics and risk communication questions. Specifically, the sample was reduced from 217 responses to 164 due to missing values and/or data entry errors. The low survey response rate can be in large part attributed to difficulties in obtaining a household member to interview 1447(59.1\%). The field research team attempted to minimize the issue by visiting households at various times including evenings and weekends, however encountering homes with no one available still presented an issue for the response rate.

Additionally for households where someone was available, low response rate can be attributed to individuals refusing to participate, in large part because of the length of the survey.

\section{- Figure 1 about here -}

In addition, although households were randomly selected from the population, a lower response rate may result in the final response sample being non-representative of the population. No individual, socio-demographic data was available on non-respondents to the survey; therefore, it was not possible to investigate response bias through a comparison of individual respondents and non-respondents. However, summary data of demographic characteristics in the city are available from the American Community Survey (ACS) data (2010) and can be used for a general comparison. As is shown in Table 1, our sample is not fully representative of the population of Newport Beach; for example, among other attributes, our sample was older, had a higher proportion of Whites, had a lower average income, and higher educational attainment.

\section{- Table 1 about here -}

\subsection{Measures}

\footnotetext{
${ }^{3}$ Response rates, while low, are in line with comparable studies elsewhere such as that in Victoria and Queensland on risk communication following the flooding of 2010-2011[36].
} 
The data presented here is taken from the results of a larger survey assessing (1) flood perception, experience, preparedness and communication methods, and (2) responses to innovative flood mapping techniques. We focus here on the risk communication components of the survey, in an effort to further our understanding of the communication of hazard risk information to flood vulnerable populations. A discussion of the variables relevant to the current study isprovided in the following sections.

As was previously discussed, past research has found that the sources utilized by households for flood risk information may vary considerably according to demographic characteristics [54]. For this reason, questions assessing demographics were included in the survey to investigate relationships between individual characteristics and methods of flood risk communication. The demographic variables collected included: age,gender, race, household income, education level, voter registration, marital status, children in household, and homeownership. Additionally, because of findings from previous studies, noting the important role previous experience with floods can play in the communication of flood risk, questions werealso included in the survey to assess flood experience. Specifically, respondents were asked whether they had ever been directly affected by a flood, and the variable was coded as binary $(\mathrm{Yes}=1, \mathrm{No}=0)$.

Information source questions were developed based on previous studies [63] and questionnaires previously developed in the context of flood risk communication [64-69]. Respondents were asked from what sources they have received information regarding flooding in the past and where they would like to receive information regarding flooding in the future. The seven information channeloptions presented to respondents included: television, radio, newspaper, printed materials, websites, Facebook, and Twitter. Due to time limitations in the 
administration of the survey, data was only collected on the channel through which the respondent received information. Data was not collected on the timing, usage, or originating location of the information source (e.g. when the information source was used, how the information was used, who was the originating body of the information source). Responses for each information source were coded as binary $(\mathrm{Yes}=1, \mathrm{No}=0)$.

The means and coding descriptions for all demographic and information source variablesare shown in Table 2.Variables were coded based on the availability of data in the larger survey

\section{- Table 2 about here -}

\subsection{Analytical Approach}

Analysis for this study involved fourphases: (1) descriptive statistics to assess the use ofhazard risk information, (2)principal component analysis (PCA) on information source indicators to identify predominant routes of dissemination for risk information, (3) correlation analysis to better understand the structure of the risk information data, and (4) logistic regression

analysis to identify predictors associated with different types of information sources used in the past or anticipated to be used in the future.

\section{Results}

The results of this first phase of analysis (descriptive statistics) are shown in in Table 2. The means for the information sources are the same as the proportion of respondents answering yes to using the source or desiring to use the source in the future; therefore, we can use these values to discuss relative popularity of different sources. For example, when considering information sources used in the past, $56.2 \%$ of the respondents used the newspaper as a source. Printed materials and television were also popular sources with $44.7 \%$ and $42.9 \%$ of the 
respondents, respectively, using the sources. Social media sites were not commonly consulted in the past for flood information. Slightly less than 3\% of the respondents used Facebook and only $2.3 \%$ used Twitter as a flood information source in the past. Of the sources of information desired in the future, the respondents to our survey favored the newspaper $(74.7 \%)$, television $(65 \%)$, and printed materials $(64.1 \%)$. Flood information via Facebook and Twitter appears to be desired more in the future than reported as used in the past (Facebook was indicated by 19.4\% of the respondents and $11.5 \%$ chose Twitter), but social media continues to be far less desired than other forms of information and knowledge dissemination sources. Interestingly, the respondents desiring to use a website for flood information in the future is about twice the number who used a website in the past for this purpose.

In the second phase, we conducteda principal component analysis (PCA) on the information source indicators to identify if sources clustered together in our survey responses. The analyses for both the past and future indicators used a promax rotation with Kaiser normalization ${ }^{4}$ and yielded two-component solutions (see Table A.1 in Appendix). The results of the PCA for the past sources accounted for $36.3 \%$ of the total variance for traditional media and $19.3 \%$ for social media. For the future sources, the analysis accounted for $40.6 \%$ or the total variance for traditional media and $18.0 \%$ for social media. The five more traditional media sources clustered together as one component (television, radio, newspaper, printed materials, and websites) and the two newer social media sources (Facebook and Twitter) clustered strongly as the second component. The results of this analysis were then used to create four dichotomous information source outcome variables; traditional media (past), social media (past), traditional media (future), and social media (future).

\footnotetext{
${ }^{4}$ A PCA factor correlation matrix revealed correlation between information source factors of 0.253 (for past) and 0.313 (for future). Therefore, it is recommended to use an oblique rotation for the most accurate representation of correlated factors $[77,78]$; therefore, a Promax rotation was specified.
} 
The thirdphase ofanalysis produced bivariate correlations between the information source variables and demographic and flood experience variables (see Table A.2 in appendix). This correlational analysis revealed statistically significant correlations between at least one of the information sources and age, gender, voter registration status, marital status, children in the household, homeownership, and flood experience. Specifically, for information received in the past, five variables were correlated with receiving information from traditional media sources (age, voter registration, marital status, homeownership and flood experience), while only one variable was significantly associated with receiving information from social media sources (voter registration). This may reflect the fact that the more active one is politically, the more attuned to social media as a vehicle for receiving general current events information one is likely to be. More research is needed to confirm this hypothesis, however. For the question about the information source preferred for receipt of information in the future, two variables were significantly correlated with wanting to receive information from traditional media sources (gender and homeownership), while five variables (age, voter registration, marital status, children in the home, and homeownership) were significantly correlated with wanting to receive information from social media sources in the future. In addition, significant inverse relationships between past and future information sources were observed for four variables (age, voter registration, marital status, and homeownership).

While bi-variate correlations may suggest some potentially important relationships, multivariable regression analysis is a more rigorous approach, which allows consideration of a set of factors or the influence of each variable controlling for all other variables in the analysis. Thus, in our last phase of analysis, we specify a logistic regression model with the sociodemographic and flood experience variables as predictors of the use of different types of 
information sources (in the past and likely to use in the future). As shown in table 3, we performed four regression analyses using each of the information sources as binary outcomes.

- Table 3 about here -

For the traditional media (past) regression model, the only significant predictor of receiving flood risk information from traditional media sources in the past was the age of the respondent. This model showed that there is a positive relationship between age and receiving flood information from traditional media in the past. Conversely, the model with social media (future) as the dependent variable shows a significant negative relationship between age and wanting to receive flood information from social media in the future. Also, in this model, being married has a negative association with the desire to receive flood information via social media in the future which may be the result of the fact that, in our sample at least, married respondents were also, in general, older. For the other models with having received information through social media in the past and, desiring to receive hazard information from traditional sources in the future as the dependent variables had comparatively little predictive power (relatively low model $\mathrm{X}^{2} \mathrm{~s}$ ). Social media (past) had no statistically significant findings and traditional (future) had only one significant coefficient. For the latter, having prior experience with flooding was associated with the desire to receive hazard information via traditional sources in the future. In the next section, we discuss these findings and their implications for policy makers.

\section{Discussion}

This study sought to assess the mechanisms through which flood risk information is currently received and desired to be received in the future by different populations in one Southern California flood-vulnerable community. Our analysis identified age as a key characteristic in understanding the previous use and future desired use of flood risk 
information.Our statistical analysis found that despite the growing popularity of utilizing social media for the communication of flood risk information, older populations tend to obtain their information on flooding from traditional media sources. In addition, not only have olderpopulations preferred receiving their information from traditional sources in the past, but they do not desire to receive information from newer media sources, such as Facebook and Twitter, in the future. Interestingly, the coefficients on age are not significant for social media in the past or traditional media in the future, although their signs are consistent with the claim that in terms of risk information sources, social media is the realm of younger persons and older people prefer traditional sources.

The finding that agepredicts the use or preference for particular kinds of risk information sources is particularly important given changes in the population distribution. Historically, the U.S. population distribution had a wide base of younger ages and a narrowing of the distribution for older ages, but this familiar "population pyramid" is transforming into a population rectangle according to the Pew Research Center [46]. That is, there will be nearly as many people at the top of the distribution as at the bottom and middle in the future. Given these population dynamics and our study's results about different preferences by age for receiving risk information, effective risk communication will require multiple communication sources and ways of communicating well into the future to ensure that all groups are informed about hazards such as flooding.Thus, we feel our findings are generalizable to other cases, due to the growing number of communities dealing with the communication of hazard information to demographically diverse communities.

The need for risk information to be delivered through multiple media, traditional and electronic, coupled with a predicted increase in the frequency of flooding in the future [47- 
48],suggests that budgets for risk communication, especially for flooding, will need to increase to ensure that sufficient resources are available to reach populations of all ages in flood vulnerable communities. This need is one of many challenges facing public officials and community groups taking responsibility for the communication of flood risk.

The current study expands on the existing literature regarding risk information and its delivery in four principal ways. First, our findings affirm what other studies have found regarding the likely role of social media in risk communication, which is that while it may amplify orsupport traditional sources of information for disasters, it is not likely to fully replace them. Past studies have noted that social media is more likely to add to the mixof sources that residents utilize for flood risk information, especially to the degree that it can connect various informal information sources to diverse groups[36]. Our finding that older populations continue to receive their flood risk information via traditional media sources despite the availability of social media sources is consistent with similar studies on risk communication. Second, our finding that older populations continue to be less receptive to receiving flood risk information from social media sources, supports discussions in the literature of the continued existence of a "digital divide" [56]. For both sets of findings, we advance the literature by providing additional case contexts - in this case, affluent coastal communities.

Third, our findings also offer an interesting contrast to other studies regarding the importance of other demographic factors such as incomein receiving information on natural hazards such as flooding. Recent studies in Kenya and elsewhere have established that factors such as income can have a dramatic impact on the ability to receive information on hazards such as meteorological forecast information[70,71]. Alternatively, our study found no significant relationships between income and information source channel. Thus, while income may play a 
key role in the communication of risk information in situations of extreme poverty, findings from our study point out that in cases where severe poverty is not an issue, income may play a much less prominent role.

Lastly, our results amplify the importance of risk information deficit models for understanding communication of flood risk. In Newport Beach our respondents were generally older and wealthier.Similar to Australian studies that have found confidence toward social media beinglinked preponderantly to younger cohorts, our study found that this information deficit principle appears to work - in reverse - for older groups within our study cohort. In this instance, older populations seem less likely to trust the internet - possibly because it is still considered by them to be "new," is in their view untested, and possibly, because it requires change. However, in order to fully asses the information deficit model, it is necessary understand the relationship of trust. Due to data limitations, it is unclear what specific role trust plays in this process, because information is not available on respondents trust towards individual information sources. Thus, research focused on the role of trust in the communication of risk information requires further investigation.

In addition, as was previously discussed, questions relating to the timing, usage and originating location of the information sources were not addressed in this study. Past studies note that understanding the timing through which hazard risk and preparedness information is received is important because it may motivate individual actions [3,4]. Similarly, assessing the ways in which specific information sources are utilized (e.g., preparedness, hazard risk information) and from what sources (e.g., governments, non-profit organizations) can also play a key role in the ways in which various information sources are utilized by communities. Thus, further research,of these critical areas of inquiry would be fruitful areas for futureinvestigation. 
Lastly, as disasters, such as floods, have multiple social, economic and political causes

underlying their magnitude - and they generate multiple consequences to different demographic groups, it is also important to understand how these underlying causes of disasters play into preferences for certain kinds of risk communications media.

\section{Conclusions}

Thedata presentedin this article are derivedfrom a larger survey assessing flood perception, experience, preparedness and communication methods, and responses to innovative flood mapping techniques associated with Flood RISE (Resilient Infrastructure and Sustainable Environments), a project aimedatascertaining ways to connect the needs of decision-makers for

practical, prescriptive advice on flood risks and their abatement with the latest research on actual risks. While survey research can help in this effort by identifying public knowledge of flooding, perception of flood hazard, and openness tovarious sources of flood risk information, whether such information can actually change behavior remains beyond the reach of survey research. Furthermore, while caution should be exercised in generalizing our results to the entire population of Newport Beach, the findings provide useful insights about risk communication for flooding and suggest possible avenues for future research.

This is the principal reason survey findings in Flood RISE will next be used to guide a series of focus groups to further establish the relevance of the spatially dynamic mapping exercise intended to provide flood hazard information to residents. Being interactive, and comprised of community opinion leaders, these groups acknowledge, as earlier noted, that diffuse actors living in flood-prone areas are motivated by divergent objectives: a fact that further impedes the communication of flood risk. This impediment must be overcome by discursive conversation and understanding among and between various community groups[72]. 
Together with the survey findings discussed here, these groups should provide further insight into trust and confidence toward more sophisticated flood risk information, and in the media through which this information should be conveyed.

Among the theoretical issues these findings amplify are the need to understand that mass media of all types can serve primarily as "conduits" of risk-related information to the public - or as themselves - "constructors' of new information. In either case, many decision makers and members of the general public are likely to receive a large proportion of risk-related information through these media, including the Internet in the case of younger populations[73-75]. The information conveyed by these media may or may not accurately convey to the viewer or reader the actual risks of a natural hazard. Nevertheless, it may influence risk perception by focusing attention on issues that people are inclined to be concerned about, reinforcing existing attitudes and values toward risk, and emphasizing the presence of conflict or uncertainty surrounding a given problem [76]. These issues will require further investigation, especially in light of the differences in user preferences toward these information sources.

\section{Acknowledgements}

This research was generously supported with funding from the National Science Foundation (Grant \#1331611). Any opinions, findings, and conclusions or recommendations expressed in this material are those of the author(s) and do not necessarily reflect the views of the National Science Foundation. The authors thank the Newport Beach Field Research Team and residents of Balboa Island, Lido Island, and the Balboa Peninsula for their participation in the Flood RISE risk perception survey. 


\section{References}

[1] G.A. Milne, W.R. Gehrels, C.W. Hughes, M.E. Tamisiea, Identifying the causes of sealevel change, Nature Geoscience. 2 (2009) 471-478. doi:10.1038/ngeo544.

[2] J.C.J.H. Aerts, W.J.W. Botzen, K. Emanuel, N. Lin, H. De Moel, Evaluating Flood Resilience Strategies for Coastal Megacities, Science. 344 (2014) 473-475. doi:10.1126/science.1248222.

[3] D.S. Mileti, J.D. Darlington, Societal response to revised earthquake probabilities in the San Francisco Bay Area, International Journal of Mass Emergencies and Disasters. 13 (1995) 119-145.

[4] D.S. Mileti, C. Fitzpatrick, B.C. Farhar, Fostering public participation for natural hazards: Lessons from the Parkfield earthquake prediction. Environment, Environment. 34 (1992) $16-39$.

[5] R.J. Burby, L.J. Steinberg, V. Basolo, The Tenure Trap: The Vulnerability of Renters to Joint Natural and Technological Disasters, Urban Affairs Review. 39 (2003) 32-58. doi:10.1177/1078087403253053.

[6] V. Basolo, L.J. Steinberg, R.J. Burby, J. Levine, a. M. Cruz, C. Huang, The Effects of Confidence in Government and Information on Perceived and Actual Preparedness for Disasters, Environment and Behavior. 41 (2008) 338-364. doi:10.1177/0013916508317222.

[7] K. Tanaka, The impact of disaster education on public preparation and mitigation for earthquakes: A cross-country comparison between Fukui, Japan and the San Francisco Bay Area, California, USA, Applied Geography. 25 (2005) 201-225. doi:10.1016/j.apgeog.2005.07.001.

[8] F.N. Burkhart, Media, emergency warnings, and citizen response, Westview Press, Boulder, CO, 1991.

[9] D.S. Mileti, S. Nathe, P. Gori, M. Greene, E. Lemersal, Public Hazards Communication and Education: The State of the Art, Natural Hazards Center, Boulder, CO, 2004.

[10] D.S. Mileti, P.W. O’Brien, Warnings during Disaster: Normalizing Communicated Risk, Social Problems. 39 (1992) 40-57. doi:10.1525/sp.1992.39.1.03x0062j.

[11] C. Chess, B.J. Hance, Communicating with the Public: Ten Questions Environmental Managers Should Ask, Center for Environmental Communication, Rutgers University, New Brunswick, 1994.

[12] J.C. Walters, H.W. Reno, Verbal Risk in Communicating Risk, in: Fourteenth Annual Department of Energy Low-Level Radioactive Waste Management Conference, Phoenix, AZ, 1992.

[13] R.E. Lundgren, A.H. McMakin, Risk communication: A Handbook for Communicating Environmental, Safety, and Health Risks, Battelle Press, Columbus, OH, 1994. http://public.eblib.com/choice/publicfullrecord.aspx?p=1192824.

[14] K.L. Ng, D.M. Hamby, Fundamentals for establishing a risk communication program, 
Health Physics. 73 (1997) 473-482. doi:10.1097/00004032-199709000-00005.

[15] A.G. Gross, The roles of rhetoric in the public understanding of science, Public Understanding of Science. 3 (1994) 3-23. doi:10.1088/0963-6625/3/1/001.

[16] P. Bennett, Understanding responses to risk: some basic findings, in: P. Bennett, K. Calman (Eds.), Risk Communication and Public Health, Oxford University Press, Oxford, 1999: pp. 3-19.

[17] J. a. Bradbury, Risk communication in environmental restoration programs, Risk Analysis. 14 (1994) 357-363. doi:10.1111/j.1539-6924.1994.tb00252.x.

[18] D. Paustenbach, Retrospective on U.S. Health Risk Assessment: How Others Can Benefit, Risk: Health, Safety, and Environment. 6 (1995) 283-333.

[19] T.L. Tinker, Putting Risk Communication Policy Into Practice: A Federal Perspective, Risk Policy Report. 4 (1997) 33-35.

[20] S. Jasanoff, The Dilemma of Environmental Democracy, Issues in Science Adn Technology. Fall (1996) 63-70.

[21] E. William Colglazier, Scientific Uncertainties, Public Policy, and Global Warming: How Sure is Sure Enough?, Policy Studies Journal. 19 (1991) 61-72. doi:10.1111/j.15410072.1991.tb01882.x.

[22] W.R. Freudenberg, J.A. Rursch, The Risks of "Putting the Numbers in Contex": A Cautionary Tale, Risk Analysis. 14 (1994) 949-958.

[23] V.T. Covello, E. Donovan, J.E. Slavick, Community outreach., Chemical Manufacturers Association, Washington, DC, 1990.

[24] A. Fekete, Safety and security target levels: Opportunities and challenges for risk management and risk communication, International Journal of Disaster Risk Reduction. 2 (2012) 67-76. doi:10.1016/j.ijdrr.2012.09.001.

[25] C. Höppner, M. Buchecker, M. Bründl, Risk Communication and Natural Hazards, CapHaz-Net WPS Report: Swiss Federal Research Institute. WP5 (2010). http://caphaznet.org/outcomes-results/CapHaz-Net_WP5_Risk-Communication2.pdf.

[26] S. Krimsky, A. Plough, Environmental Hazards: Communicating Risks as a Social Process, Auburn House Publishing Company, Dover, MA, 1988.

[27] M. Russell, Risk Communication: On the Road to Maturity, in: A. Fisher, M. Pavlova, V.T. Covello (Eds.), Evaluation and Effective Risk Communications Workshop Proceedings, Interagency Task Force on Environmental Cancer and Heart and Lung Disease, Washington, D.C., 1991: pp. 3-9.

[28] R.M. Stewart, H. Rashid, Community strategies to improve flood risk communication in the Red River Basin, Manitoba, Canada, Disasters. 35 (2011) 554-576. doi:10.1111/j.1467-7717.2010.01222.x.

[29] D. Brose, Developing a Framework for Measuring Community Resilience: Summary of a Workshop, National Academy of Sciences, Committee on Measures of Community Resilience: From Lessons Learned to Lessons Applied; Policy and Global Affairs, 
National Research Council, Washington, D.C., 2015.

[30] M.K. Lindell, R.W. Perry, The protective action decision model: theoretical modifications and additional evidence., Risk Analysis : An Official Publication of the Society for Risk Analysis. 32 (2012) 616-32. doi:10.1111/j.1539-6924.2011.01647.x.

[31] Z. Tang, L. Zhang, F. Xu, H. Vo, Examining the role of social media in California's drought risk management in 2014, Natural Hazards. 79 (2015) 171-193. doi:10.1007/s11069-015-1835-2.

[32] B.R. Lindsay, Social Media and Disasters: Current Uses, Future Options and Policy Considerations., 2011.

http://search.ebscohost.com/login.aspx?direct=true \&db=cax\&AN=79919807\&site=ehostlive.

[33] K. Mora, J. Chang, a. Beatson, C. Morahan, Public perceptions of building seismic safety following the Canterbury earthquakes: A qualitative analysis using Twitter and focus groups, International Journal of Disaster Risk Reduction. 13 (2015) 1-9. doi:10.1016/j.ijdrr.2015.03.008.

[34] K.A. Lachlan, P.R. Spence, X. Lin, M. Del Greco, Screaming into the Wind: Examining the Volume and Content of Tweets Associated with Hurricane Sandy, Communication Studies. 65 (2014) 500-518. doi:10.1080/10510974.2014.956941.

[35] J.B. Houston, J. Hawthorne, M.F. Perreault, E.H. Park, M.G. Hode, M.R. Halliwell, et al., Social media and disasters : a functional framework for social media use in disaster planning, response, and research, Disasters. 39 (2014) 1-22. doi:10.1111/disa.12092.

[36] D. Bird, M. Ling, K. Haynes, Flooding Facebook - the use of social media during the Queensland and Victorian floods, Australian Journal of Emergency Management. 27 (2012) 27-33.

http://search.informit.com.au.ezp01.library.qut.edu.au/documentSummary;dn=046814266 005608; res=IELAPA.

[37] F. Cheong, C. Cheong, Social Media Data Mining: A Social Network Analysis Of Tweets During The 2010-2011 Australian Floods, in: PACIS 2011 Proceedings, 2011: p. Paper 46. http://aisel.aisnet.org/pacis2011/46.

[38] D. Murthy, S.A. Longwell, Twitter and Disasters: The uses of Twitter during the 2010 Pakistan floods, Information, Communication \& Society. 16 (2013) 837-855. doi:10.1080/1369118X.2012.696123.

[39] S. Bunce, H. Partridge, K. Davis, Exploring information experience using social media during the 2011 Queensland Floods: a pilot study, The Australian Library Journal. 61 (2012) 34-45. doi:10.1080/00049670.2012.10722300.

[40] L.A. St. Denis, L. Palen, K.M. Anderson, Mastering Social Media: An Analysis of Jefferson County' s Communications during the 2013 Colorado Floods, in: S.R. Hiltz, M.S. Pfaff, L. Plotnick, A.C. Robinson (Eds.), Proceedings of the 11th International ISCRAM Conference, University Park, Pennsylvania, 2014.

[41] L. Palen, K. Starbird, S. Vieweg, A. Hughes, Twitter-based information distribution 
during the 2009 Red River Valley flood threat, Bulletin of the American Society for Information Science and Technology. 36 (2010) 13-17.

doi:10.1002/bult.2010.1720360505.

[42] B. Herfort, J. de Albuquerque, S.-J. Schelhorn, A. Zipf, Exploring the Geographical Relations Between Social Media and Flood Phenomena to Improve Situational Awareness: A Study About the River Elbe Flood in June 2013, in: J. Huerta, S. Schade, C. Granell (Eds.), Connecting a Digital Europe Through Location and Place, Springer International Publishing, 2014: pp. 55-71. doi:10.1007/978-3-319-03611-3_4.

[43] D. Yates, S. Paquette, Emergency knowledge management and social media technologies : A case study of the 2010 Haitian earthquake, International Journal of Information Management. 31 (2011) 6-13. doi:10.1016/j.ijinfomgt.2010.10.001.

[44] B.G. Smith, Socially distributing public relations: Twitter, Haiti, and interactivity in social media, Public Relations Review. 36 (2010) 329-335. doi:10.1016/j.pubrev.2010.08.005.

[45] M.E. Keim, E. Noji, Emergent use of social media: a new age of opportunity for disaster resilience, American Journal of Disaster Medicine. 6 (2011) 47-54. http://europepmc.org/abstract/MED/21466029.

[46] S. Muralidharan, L. Rasmussen, D. Patterson, J.H. Shin, Hope for Haiti: An analysis of Facebook and Twitter usage during the earthquake relief efforts, Public Relations Review. 37 (2011) 175-177. doi:10.1016/j.pubrev.2011.01.010.

[47] J.-Y. Jung, M. Moro, Multi-level functionality of social media in the aftermath of the Great East Japan Earthquake., Disasters. 38 (2014) S123-S143. doi:10.1111/disa.12071.

[48] K. Freberg, K. Saling, K.G. Vidoloff, G. Eosco, Using value modeling to evaluate social media messages: The case of hurricane irene, Public Relations Review. 39 (2013) 185192. doi:10.1016/j.pubrev.2013.02.010.

[49] A.L. Hughes, L.A. St. Denis, L. Palen, K.M. Anderson, Online Public Communications by Police \& Fire Services during the 2012 Hurricane Sandy, ACM Press, 2014. doi:10.1145/2556288.2557227.

[50] A. Acar, Y. Muraki, Twitter for Crisis Communication: Lessons Learned from Japan's Tsunami Disaster, International Journal of Web Based Communities. 7 (2011) 392-402. doi:10.1504/IJWBC.2011.041206.

[51] G. Mersham, Social Media and Public Information Management: The September 2009 Tsunami Threat to New Zealand, Media International Australia, Incorporating Culture \& Policy. (2010) 130-143.

[52] J. Sutton, L. Palen, I. Shklovski, Backchannels on the front lines: Emergent uses of social media in the 2007 southern California wildfires, in: F. Fiedrich, B. Van de Walle (Eds.), Proceedings of the 5th International ISCRAM Conference, 2008.

http://citeseerx.ist.psu.edu/viewdoc/download?doi=10.1.1.156.9517\&amp;rep=rep1\&amp; type=pdflnhttp://www.cs.colorado.edu/ palen/Papers/iscram08/BackchannelsISCRAM08. pdf.

[53] J. Sutton, Disaster Communication: A Call for Interdisciplinary Awareness and 
Coordinated Research, Natural Hazards Observer. 39 (2015) 14-15.

[54] K. Burningham, J. Fielding, D. Thrush, "It'll never happen to me': understanding public awareness of local flood risk, Disasters. 32 (2008) 216-238. doi:10.1111/j.03613666.2007.01036.x.

[55] M.K. Lindell, R.W. Perry, Communicating environmental risk in multiethnic communities, (2004). http://site.ebrary.com/id/10581255.

[56] M. Cretikos, K. Eastwood, C. Dalton, T. Merritt, F. Tuyl, L. Winn, et al., Household disaster preparedness and information sources: Rapid cluster survey after a storm in New South Wales, Australia., BMC Public Health. 8 (2008) 1-9. doi:10.1186/1471-2458-8195.

[57] R.G. Peters, V.T. Covello, D.B. McCallum, The determinants of trust and credibility in environmental risk communication: An empirical study., Risk Analysis. 17 (1997) 43-54.

[58] D.S. Mileti, L. Peek, The social psychology of public response to warnings of a nuclear power plant accident, Journal of Hazardous Materials. 75 (2000) 181-194. doi:10.1016/S0304-3894(00)00179-5.

[59] B. Fischhoff, Communication: Getting Straight Talk, Harvard Business Review. 8 (2006).

[60] T.W. Gallien, B.F. Sanders, R.E. Flick, Urban coastal flood prediction: Integrating wave overtopping, flood defenses and drainage, Coastal Engineering. 91 (2014) 18-28. doi:10.1016/j.coastaleng.2014.04.007.

[61] T.W. Gallien, J.E. Schubert, B.F. Sanders, Predicting Tidal Flooding of Urbanized Embayments: A Modeling Framework and Data Requirements, Coastal Engineering. 58 (2011) 567-577. doi:10.1016/j.coastaleng.2011.01.011.

[62] United States Census Bureau, American Community Survey, 2009-2013, (n.d.).

[63] D.L. Feldman, R.A. Hanahan, D. Joslin, Using Risk Information - A General Literature Review, 1998.

[64] V. Basolo, Survey of Risk Communication, Emergency Preparedness, and Internet Use, 2007.

[65] M. Kano, M.M. Wood, M.M. Kelley, L.B. Bourque, The Study of Household Preparedness: Preparing California for Earthquakes, 2009.

[66] L. Bourque, D.K. Ichinose, Study of Disaster Preparedness in Southern California Immigrant Communities, 2009.

[67] FEMA, Personal Preparedness in America: Findings from the 2012 FEMA National Survey, 2012.

[68] L.B. Bourque, M. Kano, D.S. Mileti, M.M. Wood, Questionnaires Used in the National Survey of Disaster Experiences and Preparedness (NSDEP), 2008.

[69] FEMA, 2012 Public Survey Findings on Flood Risk, 2012.

[70] Z.W. Shilenje, B.A. Ogwang, The Role of Kenya Meteorological Service in Weather Early Warning in Kenya, International Journal of Atmospheric Sciences. 2015 (2015). 
doi:10.1155/2015/302076.

[71] N. Senaratna, M.-A. Baudoin, A. Oluoko-Odingo, L. Ajuang, D. Wepukhulu, A. Mwadali, Natural Hazards and Climate Change in Kenya: Minimizing the Impacts on Vulnerable Communities Through Early Warning Systems, in: A. Singh, Z. Zommers (Eds.), Reducing Disaster: Early Warning Systems For Climate Change, Springer Netherlands, 2014: pp. 355-375. doi:10.1007/978-94-017-8598-3_19.

[72] NOAA, Introduction to Conducting Focus Groups, NOAA Coastal Services Center, Social Science Tools for Coastal Programs. (2009).

[73] A. Mazur, Technical Risk in the Mass Media, Risk: Health, Safety, and Environment. 5 (1994).

[74] J.M. Trauth, A Case Study of Health Risk Communication: What the Public Wants and What it Gets, Risk: Health, Safety, and Environment. 5 (1994).

[75] A. Maney, E. Plutzer, Scientific Information, Elite Attitudes, and the Public Debate Over Food Safety, Policy Studies Journal. 24 (1996) 42-56.

[76] B. Fischoff, Appendix C - Risk: A Guide to Controversy, in: Improving Risk Communication, National Research Council, National Academy Press, Washington, D.C., 1989: pp. 211-219.

[77] M. Matsunaga, How to Factor-Analyze Your Data Right: Do's, Don'ts, and How-To's., International Journal of Psychological Research. 3 (2010) 2011-2079.

[78] A.B. Costello, J.W. Osborne, Best Practices in Exploratory Factor Analysis: Four Recommendations for Getting the Most From Your Analysis, Practical Assessment, Research \& Evaluation. 10 (2005) 27-29. doi:10.1.1.110.9154. 
Figure 1. Newport Bay Estuary: Study Area and Survey Completion Rates

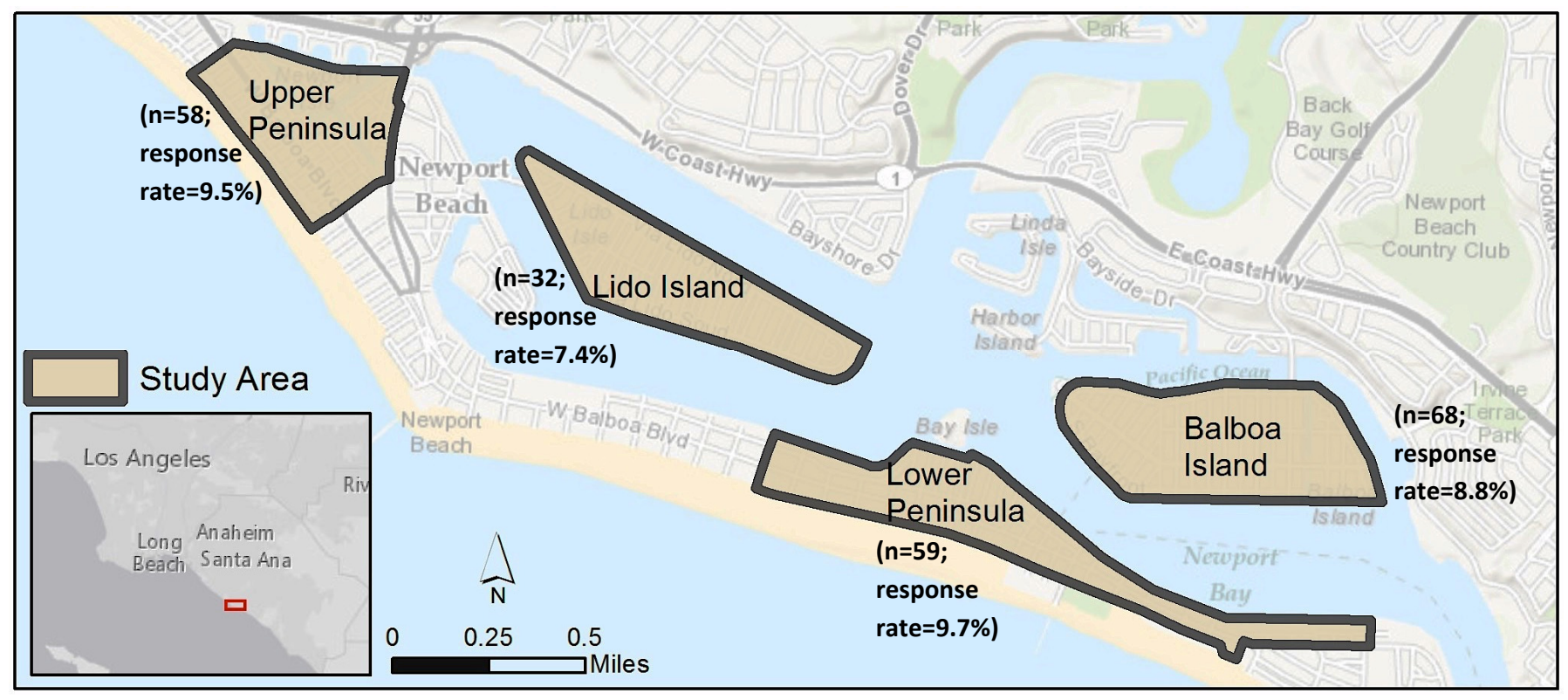


Table 1. Demographic Characteristics of the SampleCompared to 2010 American Community Survey (ACS) 5-Year Estimates

Study Sample Census Data

\begin{tabular}{lcc}
\hline Demographic Characteristics & \\
Age (in years) & $57 * *$ & 44 \\
Gender (Female) & $45 \%$ & $50 \%$ \\
Race (White) & $93.2 \% * *$ & $87.2 \%$ \\
Race (Asian/Pacific Islander) & $1.5 \% * *$ & $7 \%$ \\
Race(Black/African American) & $0.5 \%$ & $0.6 \%$ \\
Ethnicity (Hispanic/Latino) & $4.3 \% * *$ & $8.1 \%$ \\
Annual Household Income & $\$ 127,817 * *$ & $\$ 177,286$ \\
Education (BA or above) & $78 \% * *$ & $64 \%$ \\
Married & $61 \% * *$ & $50 \%$ \\
Children & $18 \%$ & $20 \%$ \\
Homeowner & $63 \% *$ & $55 \%$
\end{tabular}

Sample and census significantly different based on independent t-test $\left({ }^{*} p<.05 ;{ }^{*} p<.01\right)$. 
Table 2. Means for Demographic and Information Source Variables

\section{Description}

Mean

\begin{tabular}{|c|c|c|c|}
\hline \multicolumn{4}{|l|}{ Demographic Variables } \\
\hline Age & Age in years & \multicolumn{2}{|c|}{57.24} \\
\hline Gender & $1=$ Female; $0=$ Male & \multicolumn{2}{|c|}{0.45} \\
\hline Race & $1=$ White $; 0=$ Not White & \multicolumn{2}{|c|}{0.93} \\
\hline Income & Annual Household Income & \multicolumn{2}{|c|}{$\$ 127,817.46$} \\
\hline Education & $1=$ Completed BA or above; $0=$ Did not complete BA & \multicolumn{2}{|c|}{0.77} \\
\hline Voter & $1=$ Registered voter; $0=$ Not a registered voter & \multicolumn{2}{|c|}{0.93} \\
\hline Marital Status & $1=$ Married; $0=$ Unmarried & \multicolumn{2}{|c|}{0.61} \\
\hline Children & $1=$ Child present in home; $0=$ No child present & \multicolumn{2}{|c|}{0.18} \\
\hline Homeownership & $1=$ Homeowner; $0=$ Renter & \multicolumn{2}{|c|}{0.63} \\
\hline Flood Experience & $1=$ Experience with flooding; $0=$ No experience & \multicolumn{2}{|c|}{0.42} \\
\hline \multicolumn{2}{|c|}{ Information Source Variables } & Past & Future \\
\hline Television & $1=\mathrm{Yes} ; \mathrm{No}=0$ & 0.429 & 0.650 \\
\hline Radio & $1=\mathrm{Yes} ; \mathrm{No}=0$ & 0.258 & 0.567 \\
\hline Newspaper & $1=\mathrm{Yes} ; \mathrm{No}=0$ & 0.562 & 0.747 \\
\hline Printed Materials & $1=\mathrm{Yes} ; \mathrm{No}=0$ & 0.447 & 0.641 \\
\hline Website & $1=$ Yes $; \mathrm{No}=0$ & 0.276 & 0.548 \\
\hline Facebook & $1=$ Yes $; \mathrm{No}=0$ & 0.028 & 0.194 \\
\hline Twitter & $1=$ Yes $; \mathrm{No}=0$ & 0.023 & 0.115 \\
\hline
\end{tabular}


Table 3. Logistic Regression:Information Sources (past and future)

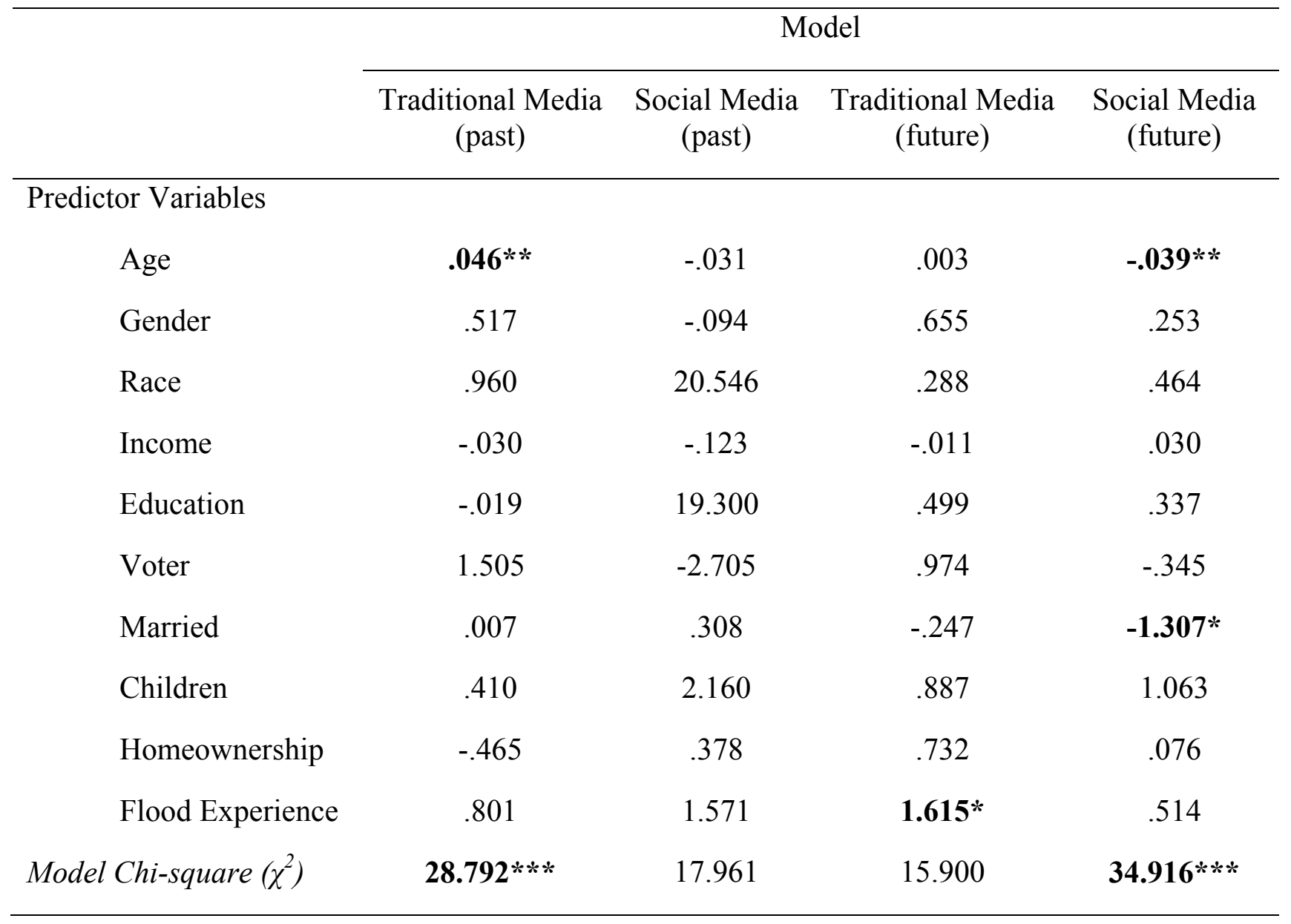

$* p<.05 . * * p<.01 . * * * p<.001$. Significant relationships are identified in bold. 


\section{APPENDIX}

Table A.1. Information Source Variables and Factor Structure

\begin{tabular}{|c|c|c|}
\hline & \multicolumn{2}{|c|}{ Rotated Factor Loading } \\
\hline & Traditional Media & Social Media \\
\hline \multicolumn{3}{|l|}{ Information Source (past) } \\
\hline Television & .717 & -.045 \\
\hline Radio & .675 & .062 \\
\hline Newspaper & .753 & -.030 \\
\hline Printed Materials & .712 & -.112 \\
\hline Website & .493 & .267 \\
\hline Facebook & -.002 & .853 \\
\hline Twitter & -.037 & .886 \\
\hline Explained variance & $36.3 \%$ & $19.3 \%$ \\
\hline \multicolumn{3}{|l|}{ Information Source (future) } \\
\hline Television & .815 & -.014 \\
\hline Radio & .781 & -.059 \\
\hline Newspaper & .794 & -.158 \\
\hline Printed Materials & .631 & .156 \\
\hline Website & .460 & .348 \\
\hline Facebook & -.010 & .848 \\
\hline Twitter & -.072 & .827 \\
\hline Explained variance & $40.6 \%$ & $18.0 \%$ \\
\hline
\end{tabular}

Values in bold indicate which items load to each factor. 
Table A.2. Bivariate Correlations

\begin{tabular}{|c|c|c|c|c|c|c|c|c|c|c|c|c|c|c|}
\hline & 1 & 2 & 3 & 4 & 5 & 6 & 7 & 8 & 9 & 10 & 11 & 12 & 13 & 14 \\
\hline 1) Age & 1.00 & & & & & & & & & & & & & \\
\hline 2) Gender & .085 & 1.00 & & & & & & & & & & & & \\
\hline 3) Race & $.210 * *$ & -.003 & 1.00 & & & & & & & & & & & \\
\hline 4) Income & $.307 * *$ & -.043 & $.192 * *$ & 1.00 & & & & & & & & & & \\
\hline 5) Education & .101 & .128 & .040 & .125 & 1.00 & & & & & & & & & \\
\hline 6) Voter & $.200 * *$ & .064 & $.147 *$ & .010 & .115 & 1.00 & & & & & & & & \\
\hline 7) Married & $.445^{* *}$ & .112 & .063 & $.436 * *$ & .118 & $.137^{*}$ & 1.00 & & & & & & & \\
\hline 8) Children & $-.273 * *$ & .112 & -.108 & $.195 * *$ & -.007 & -.028 & $.163 *$ & 1.00 & & & & & & \\
\hline 9) Homeownership & $.554 * *$ & $.139 *$ & $.179 *$ & $.409 * *$ & $.214^{* *}$ & $.287 * *$ & $.499 * *$ & -.006 & 1.00 & & & & & \\
\hline 10) Flood Experience & -.002 & -.068 & -.041 & .030 & -.042 & -.062 & -.067 & .083 & -.081 & 1.00 & & & & \\
\hline 11) Traditional Media (past) & $.240 * *$ & .073 & .109 & .067 & .027 & $.182 * *$ & $.139 *$ & .018 & $.142 *$ & $.162 *$ & 1.00 & & & \\
\hline 12) Social Media (past) & -.098 & .070 & .054 & -.098 & .107 & $-.139 *$ & -.044 & .106 & -.106 & .130 & .113 & 1.00 & & \\
\hline 13) Traditional Media (future) & .071 & $.145^{*}$ & .014 & .049 & .098 & .116 & .041 & .088 & $.162 *$ & .108 & $.319 * *$ & .002 & 1.00 & \\
\hline 14) Social Media (future) & $-.323 * *$ & .023 & -.037 & -.067 & .001 & $-.155 *$ & $-.225 * *$ & $.169 *$ & $-.208 * *$ & .096 & .037 & $.299 * *$ & $.178 * *$ & 1.00 \\
\hline
\end{tabular}

${ }^{*} p<.05 .{ }^{* *} p<.01$. Significant relationships are identified in bold. 